\title{
ASSISTÊNCIA DE ENFERMAGEM EM SAÚDE COLETIVA: ENTENDENDO O PROCESSO PARA A APLICAÇÃO DE UM INSTRUMENTO TRANSFORMADOR DA PRÁTICAEDATEORIA.
}

\author{
Emiko Yoshikawa Egry * \\ Rosa Maria Godoy Serpa da Fonseca* \\ Maria Rita Bertozzi**
}

RESUMO: As autoras discutem a operacionalização do Método de Assistência de Enfermagem em Saúde Coletiva (MAESC), orientada pelo materialismo histórico e dialético. A bordam os temas relativos à perspectiva epistemológica; aos pressupostos para a operacionalização; à totalidade e suas dimensões; às etapas; e finalmente, à condução praxiológica. Concluem, instigando os pesquisadores a se utilizarem deste instrumento, abrindo, para tanto, decodificadores mais refinados que se aproximem da real prática assistencial de enfermagem no nivel local de atenção à saúde.

ABSTRACT: The authors discuss the application of the Collective Health Nursing Assistance, grounded on dialectical and historical materialism. They explain the issues concerning to epistemologial perspective, the presupposition to apply, the totality and its dimensions, the leading phasis and, finally, the praxiological process.

UNITERMOS: Metodologia de assistência de enfermagem - Saúde coletiva Materialismo histórico e dialético.

\section{INTRODUÇÃO}

A apresentação pública de um método de assistência de enfermagem, com orientação bastante distinta de outros que estão sendo adotados na enfermagem data de 1987 , dentro do $39^{\circ}$ Congresso Brasileiro deEnfermagem, em que foi divulgado, comotemalivre, otrabalho intitulado 'Bases metodológicas para a assistência de enfermagem em saúde coletiva fundamentadas no materialismo histórico e dialético" ${ }^{\prime 3}$. Nele tentamos explicar pela primeira vezo método de assistência de enfermagem baseado no referencial materialista histórico e dialético. Procuramos destacar as concepções mais utilizadas, e nisso houve a preocupação maior de aclarar o entendimento do conceito de sociedade segundo esta visão de mundo. Além disso, foram descritos os pressupostos e a forma de utilização, englobando as etapas e a maneira de desenvolvê-lo.

Dois anos mais tarde, em um evento regional do estado de São Paulo foi colocado em discussão o texto "Sistematização da assistência de enfermagem em saúde coletiva orientada pelo materialismo histórico e dialético: em busca do horizonte de unicidade entre o saber e o fazer's. Importava, desta vez, destacar os pressupostos dessa assistência e uma melhor explicitação a partirdeles, das etapas de desenvolvi nento desse método.

A utilização inédita deste instrumento para a assistência de enfermagem à família, enquanto foco privilegiado de recorte, foi realizado junto aos usuários das Unidades Básicas de Saúde do

* Enfermeira. Professora Doutorada do Departamento de Enfermagem de Saúde Coletiva da Escola de Enfermagem aa Universidade de São Paulo.

** Enfermeira. Professora Assistente do Departamento de Enfermagem de Saúde Coletiva da Escola de Enfermagem da Universidade de São Paulo. 
Município de Taboão da Serra, São Paulo, ${ }^{4}$ e em Florianópolis, Santa Catarina ${ }^{6}$, revelando em ambos os estudos tanto suas possibilidades quanto suas limitações/contradições. Num outro recorte fenomênico, ARAÚJO ${ }^{1}$ estudou a prática de enfermagem junto à mulher que amamenta, aplicando este método de assistência de enfermagem. Neste, mais claramente que em outros estudos, pode-se verificar concretamente a necessidade premente de se elucidar as categorias analíticas que devem ser abertas para se aproximar do fenômeno, para poder dar prosseguimento ao processo de totalização social. Por se tratar de estudo que lida com a mulher, a categoria social central deveria ser o gênero, entendido como sexo socialmente construído.

Para que esse método possa ser melhor compreendido, e portanto, passivel de serutilizado na prática assistencial de enfermagem, ressaltamos, neste momento, algumas questões relativas ao entendimento do processo para a aplicaçãodo método enquanto instrumento. Desde já, é necessário afirmar que não pretendemos esgotar todas as questões que esse método impõe à sua operacionalização, pois de acordo com o próprio elemento constitutivo dele, ou seja, do movimento de transformação, a própria operacionalização desdobrará outras questões que, neste momento, parecem estar ausentes.

\section{A VISÃODE MUNDO COMOPONTODEPARTIDA: A PERSPECTNAEPISTEMOLÓGICA DO MÉTODO}

A adoção do referencial materialista histórico e dialético e de suas leis e categorias para fundamentar este método de assistência de enfermagem, pressupõe a superação da visão idealista de mundo. A visão de mundo pode ser entendida, de acordo com KRAPIVINE ${ }^{9}$, como "um conjunto de princípios, pontos de vista e convicções que determinam a atitude do homem em relação à realidade e a si próprio, a orientação da atividade de cada pessoa concreta, grupo social, classe ou sociedade em geral".

Duas visões de mundo podem serdestacadas: a idealista e a materialista histórica e dialética.

O idealismo parte do princípio de que a consciência ou qualquer das suas manifestações como o pensamento, a vontade ou qualquer coisa de ideal e imaterial, é primário, fundamental e determinante. Por outro lado, a matéria, a natureza, o mundo material, são produzidos por aqueles ou dele dependentes ${ }^{5}$.

Em oposição a isto, o materialismo consideraque omundoé, pela suanatureza, material, ou seja, ele existe fora da consciência humana e independente dela, não sendo produto nem do pensamento, nem de qualquer ser imaterial" 5 .

Ainda, pressupõe que toda a matéria está em constante desenvolvimento e transformação, não de modo caótico, mas segundo determinadas leis.

A adoção desta visão de mundo requer, por conseguinte, a negação do reducionismo simplista do processo saúde-doença, superando o modelo unicausal dadoença, o modelo multicausal que se "limita a descobrir fatores causais na produção de problemas fáceis de atacar, commedidas baratas e que permitam implementar medidas coletivas de controle" ${ }^{2}$. Trata-se também de superar a triade ecológica de Leavell e Clarck, pois nele ignora-se a categoria social do Homem, transformando-o em fator eminentemente biolígico ${ }^{2}$.

Trata-se de compreenderque o processo saúdedoença

manifesta-se através de diferentes fenômenos cuja frequência e intensidade variam com o tempo e espaço, expressos anívelde indivíduos, de classes ou grupos sociais e das formações econômicas e sociais. Nos individuos manifesta-se com variações na frequência eintensidade entre pessoas ou grupos que se diferenciam entre si pelos seus atributos individuais, tais como: sexo, idade, etc..(..) Nas classes sociais e nos grupos da população que compartem entre si similares condições de vida e de trabalho manifesta-se como perfis de saúde-doença diferenciais entre essas classes. Anivelde formações econômicosociais e de grandes grupos de população que compartem o fato de estar vinculado a uma mesma estrutura e superestrutura(...) os fenômenos de saúde-doença manifestam-se como perfis de saúdedoença peculiares destas formações econômico-sociais e como variações destes perfis à medida em que variam os processos estruturais e superestruturais que as caracterizam ${ }^{8}$.

Tal forma de perceber o processo saúdedoença advém da concepção de sociedade e 
homem coerente com a visão materialista e dialética de mundo. Da mesma maneira, as concepções de assistência à saúde coletiva, bem como a enfermagem, estão atreladas à mesma visão.

A assistência à saúde coletiva é conceituada como sendo a interferência consciente (sistematizada, planejadae dinâmica) no processo saúde-doença de uma dada coletividade, consideradas as distinções dos grupos sociais, realizadapelo conjunto dostrabalhad ores de saúde com coletividade, objetivando a transformação do perfil de saúde-doença ${ }^{13}$.

Podemos prontamente perceber que esta concepção de assistência em saúde coletiva não seencontra operando, expressivamente, na prática, uma vez que tambémnãose encontram operando as concepções a ela correlatas, ou seja, de sociedade e de processo saúde-doença. A visão idealista de mundo com as correspondentes conceptualizações, estão ainda permeando fortemente a nossa prática em saúde.

A questão epistemológica se faz presente à medida em que as concepções que permeiam a nossa prática são por sua vez mediadas e originárias de uma dada visão de mundo e que, neste momento, ao tentar tornar possível a utilização do método dentro da visão materialista histórica e dialética, devem ser elas claramente expressas. Melhor dizendo, não se trata de entender somente as etapas e sim de buscar compreender porque, para que e com quem desenvolvertal proposta de método.

\section{PRESSUPOSTOSDAOPERACIONALIZAÇÃO DO MÉTODO: A QUESTÃO DAS AMARRAS ARTICULADAS}

Desde que a proposição deste método está explicitamente posta dentro de um referencial teórico-filosófico, há necessidade de recolocaros pressupostos e leis que fazem a articulação das partes, sem o que ele se torna mera alternância de fases, ou troca de denominações até então utilizadas por outras proposições de sistematização da assistência, embasadas em outros referenciais.

Asleis que percorrem o método sãoas trêsleis fundamentais da dialética, ou seja: a leida unidade e luta dos contrários; a leidatransição de mudança quantitativa para a qualidade; e a leida negação da negação.

Subordinado a estas leis, ocorre o processo de desenvolvimento que a teoria materialista dialética sustenta como sendo:

1) o que desencadeia e impulsiona o desenvolvimento são as contradições internas, ou seja, o choque de várias forças e tendências que são inerentes a um determinado fenômeno; 2) há uma conexão indissolúvel e uma mútua dependência entre todos os aspectos dos fenômenos; 3) o processo de desenvolvimento não é uniforme egradual, mas apresenta episódios de reviravoltas, saltos e revoluções que se iniciam pela acumulação gradativa em quantidade para, em um dado momento posterior, seguir-se a passagem parauma nova qualidade; 4) o processo de desenvolvimento não é linear, antes, pode ser comparado a uma espiral, porque os estágios podem parecerque são percorridos várias vezes, só que, a cada aparente repetição, retorna-se ao anterior, porém, num nivel superior ${ }^{5}$

Os pressupostos essenciais que articulam o método, de acordo com EGRY ${ }^{3}$, são:

- Dinamicidade - que significa que toda a realidade social está em contínua transformação, sofrendo sucessivas modificações no tempo e no espaço. A sociedade, o processo saúde-doença, assim como o processo assistencial nãoescapam desta dinamicidade.

- Historicidade - que advém do entendimento de Engels, que designa uma visão do desenrolar da história, que procura a grande força motriz de todos os acontecimentos históricos importantes no desenvolvimento econômico da sociedade, nas transformações do modo de produção e de troca na consequente divisão da sociedade em classes e na luta entre as classes.

- Participação-que é expressa no processo de manifestação das vontades pessoais no contexto do grupo, para que estas (as vontades) sofram as ampliações que Ihes impõem as contraposições das vontades alheias; com isto, as pessoas podem compreender as articulações entre as diferentes dimensões do objeto fenomênico e em conjunto construir alternativas de equacionamento das questões, agora dentro de perspectivas grupais. Ou ainda, como refere HENRIQUES ${ }^{7}$,

a participação está em estreita vinculação com o processo de consciência social. Os homens modelam a sociedade segundo sua consciência, porém, esta modelagem 
émediada pela propria sociedade. Nenhuma transformação social é um ato de um homem só, resulta ela da verdadeira natureza da sociedade pelas parcelas das massas que asconstituem. Nas sociedades divididas em classes antagônicas (nosso caso), toda a superestrutura (o aparelho do Estado, suas instituições jurídicas, religiosas, órgãos de representação, as universidades, os meios de comunicação, etc.) está, se considerada em seu conjunto, voltada para manternas massas, a idéia de que a ordem social é justa, legítima ou até mesmo sagrada, a fim de que cada um cumpra as tarefas que lhes cabem e das quais depende a viabilidade da própria sociedade. Cabe ao processo participativo desmistificar o interesse predominante na manutenção da ordem social vigente.

- Horizonte - é a antevisão da qualidade nova que se quer chegar, enquanto lugar, conteúdo e processo; não sendo meramente objetivo, ou meta, ele é continuamente re-situado e re-dimensionado no decorrer do caminho para o seu alcance. Articulado aos pressupostos anteriores, ele é dinâmico, histórico e formulado em conjunto com os diferentes atores sociais que partilham a intervenção no processo saúde doença.

\section{A APROXIMAÇÃO DA REALIDADE OBJETIVA ATRAVÉSDASTRÊSDIMENSÖESDAREALIDADE: AQUESTÃODATOTALIDADE}

O caráter histórico, bem como, a natureza dialética do processo interventivo, exigem que se leve em consideração o conjunto de fenômenos que operam a realidade social, ou seja, a totalidade, como a concebe LUKÁCS ${ }^{11}$. De acordo com este autor, a compreensão dialético-materialista da totalidade compreende: em primeiro lugar, o caráter interativo da unidade concreta de contradições existentes numa dada totalidade; em segundo, o caráterde relativização de posição toda totalidade contém totalidades inferiores a ela subordinadas e por sua vez, ela está sobredeterminada por uma outra de complexidade superior; e em terceiro lugar, o caráter da sua relatividade histórica, ou seja, da mutabilidade, da limitabilidade espaciale temporal de sua existência.

Para que se possa apreender a totalidade na assistência de enfermagem, a realidade objetiva, ou seja, o processo saúde-doença da coletividade, esta deve ser aproximada desdobrando-se em três dimensões: a estrutural, a particular e a singular.

A dimensão estrutural compreende os processos de desenvolvimento da capacidade produtiva e do desenvolvimento das relações de produção, da formação econômica e social e das formas político-ideológicas derivadas.

A dimensão particular compreende os processos de reprodução social, manifestos nos perfis epidemiológicos de classe, integrados pelo perfil reprodutivo de classe e perfil saúde-doença, e formas especiais de prática e ideologia em saúde.

MARX ${ }^{12}$ explica a reprodução social: qualquer que seja a forma social do processo de reprodução, ele tem de ser contínuo, deve repetir periodicamene as mesmas fases. Uma sociedade não pode deixarde produzir, como não pode deixarde consumir. Portanto, quando visto como um todo interligado, e no fluxo constante de suarenovação permanente, todo o processo social de produção é, ao mesmo tempo, um processo de reprodução.

No processo de trabalho, a unidade de produção e reprodução pode ser tomada separadamente, correspondendo ao momento produtivo aquele no qual

o homem produz os bens desgastando-se ao consumir sua força de trabalho, e o momento reprodutivo durante o qual o homem consome os bens reproduzindose. (...) Cada momento produtivo corresponde a um momento reprodutivo particular, e da combinação de ambos dependem os padrões de desgastereproduçãoqueoriginamo processo saúdedoença dos grupos sociais ${ }^{8}$.

Adimensão singular compreende os processos que, em última instância, levam a adoecer e a morrerou, ao contrário, a desenvolvero nexo biopsíquico dado pelo seu funcionamento, consumotrabalho individual e pelas formas de participação individual de organização e consciência ${ }^{13}$.

Com esta aproximação, é possivel descobrir as inúmeras concatenações ocultas que frequentemente mascaramo objeto d e intervenção (processo saúde-doença de um dado grupo social) conduzindo paulatinamente ao entendimento/ apreensão da totalidade exposta dialeticamente ${ }^{13}$. 
ETAPAS DO MÉTODO: a questão da articulação para operacionalização orientada pela materialismo histórico e dialético

Ométodo de assistência de enfermagem (neste referencial) é um instrumento do processo de trabalho, que permite intervirno objeto-processo saúde-doença da coletividade, mais diretamente referido à singularidade, através de aproximações sucessivas com a realidade objetiva - processo saúde-doença mais referido à particularidade e à estruturalidade de dado grupo social - no sentido de transformá-lo qualitativamente.

As etapas propostas para o desenvolvimento do método, de acordo com QUEIROZ e EGRY ${ }^{13}$, apesar de serem apresentadas sequencialmente para facilitar a sua compreensão, guardamentre si a relação de interpenetrabilidade, ou seja, cada uma delas está fortemente articulada e é componente da mesma totalidade - a intervenção consciente (refletida, conseqüente e intencional) no processo saúde-doença.

No seu desenrolar observa-se, entretanto, que as etapas revelam momentos hegemônicos de abordagem. Istoquerdizerque, em dado momento, uma delas está mais destacada do que as demais, para o aprofundamento de determinada fase. $\mathrm{Da}$ mesma maneira, as dimensões da realidade objetiva serảo aproximadas, operando com certa relevância uma ou outra. Importa neste percurso compreender que as dimensões fazem parte da mesmatotalidade, estando fortemente articuladas entre si e, que sem a visualização de todas, mesmo em níveis de destaque distintos, não se pode apreender a dada totalidade. Ressalte-se que a totalidade não é apreensivel inteiramente, poiselaé móvele mutável, portanto, esta apreensão significa tão somente a realização de processos contínuos de totalização.

\section{Primeira etapa: Captação da realidade objetiva}

O conhecimento da realidade objetiva através dastrêsdimensões, se faz a partirdolevantamento de dados que permitam visualizar a situacionalidade, ou seja, como o objeto fenomênico encontra-se posto neste momento, a sua concatenação com as transformaçõesque se sucederam (historicidade), e no modo como estas transformações ocorreram (dinâmica). Deve necessariamente ser um processo participativo, na medida em que importa conhecer como o sujeito do processo assistencial percebe a realidade em que se insere, e da forma como percebe.

Para compor, numa primeira instância, os dados da dimensão estrutural, é necessário que se recoloque: forma de organização social, políticas de saúde, destinação destas políticas e as instituições de saúde.

A composição da dimensão particular é realizada atravésdaexplicitação da situcionalidade, dinâmica e historicidade do processo saúdedoença nos diferentes grupos sociais, destacandose aquele pertencente ao sujeito da intervenção. Além disto, há que se considerar a dinâmica situacionale a historicidade dos perfis reprodutivos de classe e das formas especiais de prática e de ideologia em saúde de distintos grupos sociais. As organizações e movimentos populares são pertinentes a esta dimensão. No Brasil, até este momento, os dados sobremortalidade e morbidade não estão discriminados por grupos sociais (classes sociais) e isto acaba tornando-se o principal obstáculo para a compreensão mais aprofundada desta dimensão, assim como para a correspondente interpretação e construção do projeto de intervenção.

Adimensão singular é composta pela dinâmica, historicidade e situcionalidade dos processos de sobrevivência e/ou aperfeiçoamento dos grupos sociais enquanto riscos e potencialidades mais proximais que afetam diretamente o nexo biopsíquico. Devem serlevantados dados relativos ao: trabalho (vinculação, remuneração, jornada, ambiente físico, etc), habitação (ambiente físico, espaço, propriedade, localização, mobilidade, aparelho urbano, etc.), educação (acesso, educação formal/não formal, fontes de obtenção detemática para reflexão, etc.), relaçõesfamiliares e grupais (qualidade, oportunidade, coesão, vida reprodutiva, etc.), alimentação (acesso, qualidade, produção, etc.), corpo bio-psíquico (domínio, desgaste, sensações, funcionamento do corpo, tematização ou representação dos processos de saúde-doença,etc.), prazer (quantidade, qualidade, participação individual ou grupal, etc.), transporte (acesso, tempo gasto, propriedade, etc.) ${ }^{13}$.

\section{Segunda etapa: Interpretação da realidade objetiva}

As contradições existentes entre e inter dimensões e seus grupos temáticos são 
evidenciados nesta fase. A interpretação da realidade objetiva subjaz à visão de mundo e por isso torna-se tão mais difícil quanto maior for a consciência ingênua dos partícipes, ou seja, a sua alienação. A alienação caracteriza-se, segundo LANE ${ }^{10}$,

pela atribuição da naturalidade aos fatos sociais; esta inversão do humano, do social, do histórico como manifestação da natureza, faz com que todo o conhecimento seja avaliado emtermos de verdadeiro ou falso e de universal; neste processo a consciência é reificada, negando-se como processo.

Nesta fase de interpretação da realidade objetiva, os conhecimentos teórico-práticos existentes até o momento são considerados, e à luz deles, é que se podeverificar, principalmente, a contradição teórico-prática. Desta forma, os avançostecnológicos, bem como novas maneiras de compreendero processo saúde-doença, devem ser recolocados.

\section{Terceira etapa: construção do Projeto de intervenção}

O projeto de intervenção na realidade objetiva deve conter proposições que abarquem as três dimensões, hierarquicamente postas, mesmoque provisoriamente, dadoquetal hierarquia é flexível e mutável adepender do foco proximal que se quer elucidar. Para tal hierarquização, os grupos temáticos devem sofrer rigoroso exame à luz da: vulnerabilidade de conteúdo, ou seja, da possibilidade concreta de interver pelo saber/não saber existente; vulnerabilidade espacial e temporal, queé dada pela oportunidade, ou época, em que poderá haver o ponto de ruptura; vulnerabilidade de forma, ou seja, da existência, ou não, de estratégias de intervenção que possibilitem o rompimento.

Oprojetode intervençãodeve conter: objetivos, definição das responsabilidades dos partícipes e cronograma de execução com as respectivas estratégias.

De acordo com os pressupostos metodológicos, o projeto é mutável, sofrendo substanciais modificações no desenvolver do processo, em decorrência de novos dados captados, da reinterpretação dos dados e dos resultados da intervenção. O projeto deve ser continuadamentereelaborado, mesmo assim, em todas as versões há necessidade de se explicitar claramente as proposições. Isto permitirá captar a dinâmica das transformações ocorridas decorrentes da reinterpretação continuada e aprofundada, revelando, porsisó, o movimento de consciência.

\section{Quarta etapa: intervenção na realidade objetiva}

Nesta etapa são executadas as proposições contidas no projeto. Inicialmente podehavermaior tendência em concentrar as ações dentro da dimensão singular. Isto decorre como produto de nossa formação profissional, onde há absoluta hegemonia das ações biologizantes, desconsiderando a inserção do homem na sociedade. E também, o resultado histórico dos investimentosvalorativosque vêmsendorealizados no campo da saúde. Ainda que inicialmente assim proceda, o desenvolvimento do método exige que as demais dimensões sejam lidadas de modoque possibilite concatenar os temas, articuladamente, dentro da totalidade, sem o qu. tornaria apenas um "fator biologico", contrariando a natureza dimensional da singularidade.

\section{Quinta etapa: reintepretação da realidade objetiva}

Tão importante quanto as demais etapas, a reinterpretação possibilita a avaliação do alcance das proposições, a compreensão das facilidades e dificuldades no desenvolvimento do processo, bem como, a visualização da dinâmica que se instalou nele. O exame acurado da historicidade, da dinâmica, da participação e do horizonte, permitirá re-situar as proposições acrescidas de novos grupos temáticos que surgirão durante 0 processo assistencial.

A operacionalização deste método exige que a totalidade seja gradativamente aproximada, articulando-se firmemente as suas partes, ou sejam, as dimensões, com os pressupostos e as leis da dialética materialista.

\section{O MÉTODO COMO INSTRUMENTO E COMO PROCESSODETRABALHONAENFERMAGEM:a questão da condução praxiológica}

A interferência consciente (refletida, conseqüentee intencional) em uma dadarealidade objetiva, não se dá apenas no momento da 
assistência, mesmo porque ela não pode ser isolada do contexto das relações que estabelecem os trabalhadores de saúde em geral, e particularmente, os da enfermagem. Uma vez que o método exige a compreensão dos fenômenos sob determinada visão de mundo, os agentes sociais envolvidos no processo assistencial de enfermagem necessitam re-situar os conceitos e concepções presentes, compreendê-los dentro da totalidade e analisá-los na sua historicidade, dinamicidade, horizonte e participação. Háquese aclarar gradativamente cada uma das concepções e pressupostos à luz da vivência pessoal e profissional, num processo coletivo de reflexão acerca do seu trabalho.

Dessa maneira, a possibilidade de tornar operacional o método ora examinado pressupõe um processo continuado de reflexão acerca de nossa prática profissional, re-situados dentro da ótica materialista dialética e histórica de mundo. Nesse processo, as concepções mais presentes em nossa profissão, tais como sociedade, homem, processso saúde-doença, enfermagem, assistência de enfermagem deverão ser reconceptualizados, através de sucessivos movimentos que contemplem o repensar crítico sobre a realidade objetiva de nosso trabalho.

\section{CONCLUSÃO}

A utilização correta do Método de Assistência de Enfermagem orientada pelo materialismo histórico e dialético, enquanto um instrumento do processo de trabalho assistencial, deve ser fortemente embasada na compreensão de suas raízes teórico-filosóficas, sem o que se torna um mero roteiro a ser seguido. Portanto, o caráter processual, praxiológico e totalizante deve ser minuciosamente elucidado, a fim de que, à sua operacionalização, não se caia na armadilha de desconectar os elementos constitutivos dos processos de trabalho, ou seja a Finalidade, os Meios e Instrumento e o Objeto. Mesmo assim, na fase de reinterpretação, é preciso re-examinar, também, as contradições existentes no saber ideológico que orienta o processo de trabalho da assistência de enfermagem.

Ao aplicar o instrumento, cada pesquisador deve procurar elaborar decodificadores mais refinados, que possibilitem a intervençãono objeto, considerando-se as singularidades, tanto do processo saúde-doença, quanto do processo de produção dos serviços de saúde.

\section{REFERÊNCIAS BIBLIOGRÁFICAS}

1 - ARAÚJO, L.D.S. A prática da mulher que amamenta tendo como base um marco conceitual fundamentado nomaterialismo histórico e na teoria das representações sociais: amamentar, uma opçăo consciente? Trabalho apresentado à disciplina $\mathrm{d} e$ Prática Assistencial do Curso de Mestrado em Enfermagem da Universidade Federal de Santa Catarina. Florianópolis, 1989. 86p. (mimeo).

2 - BREILH, J. e GRANDA, E. Investigação da saúde na sociedade: guia pedagógico sobre novo método epide miológico. São Paulo: Instituto da Saúde/ ABRASCO, 1986.

3 - EGRY, E.Y. A sistematização da assistência de enfermagem em saúde coletiva orientada pelo materialismo histórico dialético: em busca do horizonte da unicidade entre o saber e o fazer. IN: SEMANAWANDA DE AGUIAR HORTA, 3, 1989, São Paulo Anais... São Paulo, Escola de Enfermagem da USP, 1989.

4 - EGRY, E.Y. e BERTOLOZZI, M.R. Assisténcia de enfermagem à familia fundamentada no materialismo histórico e dialético: da proposiçăo teórica ao ensaio da prática./Trabalho apresentado no Curso de Extensão Universitária "Pesquisa e Prática da Enfermagem" da Escola de Enfermagem de Ribeirão Preto da Universidade de São Paulo. São Paulo, 1988 (mimeografado).
5 - FONSECA, R.M.G.S. da. Mulher, reprodução biológica e classe social: a compreensão do nexo coesivo através do estudo dialético do perfil reprodutivo biológico de mulheres atendidas nas Unidades Básicas de Saúde. São Paulo, 1990. 336 p. Tese (Doutorado) Escola de Enfermagem, Universidade de São Paulo, 1990.

6 - GHIORZI, A.R. Possibilidades e limites para uma prática transformadora na enfermagem familiar. Florianópolis, 1991. 230 p. Dissertação (Mestrado) Curso de Pós-graduação do Centro de Ciências da Saúde da Universidade Federal de Santa Catarina, 1991.

7 - HENRIQUES, S.B. A ciência e a filosofia. Ci. e Cult., Săo Paulo, v.33, n.2, p 198-212, fev., 1981.

8 - INFANTE, N.B. e ALVAREZ, L. Los procesos de trabajo $y$ de salud-enferme dad: una relación dialectica. Educ.Med. Salud, v..21, n.2, p.92-105, 1987.

9 - KRAPIVINE, V.V. Filosofia marxista-leninista fundamentos científicos e método de estudo Moscou: Progresso, 1984.

10- LANE, S.T.M. Consciência e alienaçăo: a ideologia a nivel individual. IN: LANE, S.T.M. e W. CODO. Psicologia social: o homem em movimento. São Paulo: Brasiliense, 1984. 
11 - LUKÁCS, G. Historia y consciencia de clase: estudios de dialéctica marxista. México: Grijalbo, 1969.

12- MARX, K. O Capital. Livro I. Såo Paulo, Bertrand BrasilDIFEL, 1987.
13- QUEIROZ, V.M. e EGRY, E.Y. Bases metodológicas para a assistência de enfermagem em saúde coletiva fundamentadas no materialismo histórico e dialético. Rev. Bras. Enf., v.41, n1, p.26-33, jan/mar 1988.

Recebido para publicaçăo em 1\%/8/94 